\title{
Association of Tumor Necrosis Factor $\alpha$ and Manganese Superoxide Dismutase Polymorphisms in Patients with Non-Alcoholic Steatohepatitis from Northeast Mexico
}

\author{
Karina Trujillo-Murillo ${ }^{1,6}$, Francisco J. Bosques-Padilla ${ }^{2}$, Irma Calderón-Lozano ${ }^{2}$, \\ Sirelda Navar-Vizcarra ${ }^{2}$, Elvira Garza-González ${ }^{3}$, Alberto Niderhauser-García ${ }^{4}$, \\ Juan P. Flores-Gutiérrez ${ }^{4}$, Pablo Zorrilla-Blanco ${ }^{5}$, Ricardo Salinas-Garza ${ }^{2}$, \\ Ana M. Rivas-Estilla ${ }^{1}$ and Herminia G. Martínez-Rodríguez ${ }^{*}, 1$
}

\begin{abstract}
${ }^{1}$ Departments of Biochemistry and Molecular Medicine, ${ }^{2}$ Gastroenterology, ${ }^{3}$ Microbiology and ${ }^{4}$ Pathology, School of Medicine and University Hospital "Dr. Jose E. Gonzalez", Autonomous University of Nuevo Leon, and the ${ }^{5}$ Hidalgo Clinic, Monterrey, Nuevo Leon, Mexico. ${ }^{6}$ Mesoamerican Center Studies in Public Health and Disasters (CEMESAD), Autonomous University of Chiapas, Mexico
\end{abstract}

\begin{abstract}
Background and Aims: Environmental and genetic factors play a role in the pathogenesis and natural history of non-alcoholic steatohepatitis (NASH). The aim of this study was to determine if the G-238A (allele TNFA) and G-308A (allele TNF2) tumor necrosis factor-alpha (TNF- $\alpha$ ) and Ala9Val manganese superoxide dismutase (MnSOD) polymorphisms were associated with NASH in a case-control study of subjects from Northeast Mexico. Methods: We analyzed DNA samples from 68 patients with NASH (50 women and 18 men; mean age \pm SD, $33.9 \pm 10.8$ years; BMI $43.9 \pm 7.2 \mathrm{~kg} / \mathrm{m}^{2}$ ) and 100 healthy subjects (44 women and $56 \mathrm{men}$; mean age $\pm \mathrm{SD}, 27.8 \pm 10.8$ years; BMI $23 \pm 1.6$ $\mathrm{kg} / \mathrm{m}^{2}$ ). The diagnosis was based on liver biopsy reviewed by two pathologists blinded to clinical data. The polymorphisms were evaluated using the polymerase chain reaction-restriction fragment length polymorphism method. Results: The frequency of G-238A TNF- $\alpha$ and Ala9Val MnSOD polymorphisms in NASH patients was significantly higher in comparison with control subjects $(\mathrm{OR}=3.06,95 \% \mathrm{CI} 1.29-7.33, p=0.0047$ and $\mathrm{OR}=6.28,95 \%$ CI $2.95-13.55$, $p=0.001$, respectively). In contrast, the G-308A TNF- $\alpha$ polymorphism did not show a statistical difference between either group $(\mathrm{OR}=1.04,95 \%$ CI $0.45-2.38, p=\mathrm{NS})$. Analyzed populations were in Hardy-Weinberg equilibrium. Conclusions: Our results suggest that G-238A TNF- $\alpha$ and Ala9Val MnSOD polymorphisms, which are molecules involved in inflammation and cellular oxidative stress, could be associated with NASH. These data may contribute to understanding the genetic susceptibility to NASH.
\end{abstract}

Keywords: Non-alcoholic steatohepatitis (NASH), morbidly obese, tumor necrosis factor alpha (TNF- $\alpha$ ), manganese superoxide dismutase (MnSOD), polymorphisms.

\section{INTRODUCTION}

Non-alcoholic fatty liver disease (NAFLD) is the most frequent cause of abnormal hepatic steatosis in the absence of alcohol abuse world-wide. Non-alcoholic steatohepatitis (NASH) is the most progressive form of NAFLD. Little is known about the pathogenesis and natural history of NASH; however, it has been reported that environmental and genetic factors act in concert. Various risk factors have been associated with NASH, such as insulin resistance (IR) [1], obesity, type 2 diabetes mellitus, hypercholesterolemia, drugs, toxins [2,3], mitochondrial dysfunction, and oxidative stress [4]. Recently, polymorphisms in genes that play a role in lipid metabolism and steatosis, the insulin signaling pathway, reactive oxygen species (ROS) formation and degradation, cytokines and endotoxin receptors, and profibrogenic

*Address correspondence to this author at the Department of Biochemistry and Molecular Medicine, School of Medicine, Autonomous University of Nuevo Leon, Monterrey, NL, Mexico; Tel: (52-81) 8329-4174; Fax: (52-81) 8333-7747; E-mail: herminiamar@gmail.com mediators are of special interest because it has been proposed that they increase the risk of developing NASH $[5,6]$.

$\mathrm{G}$ to A polymorphic sequence at position -308 (TNF1 to TNF2 allele) and -238 (TNFG to TNFA allele) in the tumor necrosis factor alpha (TNF- $\alpha$ ) gene promoter region has been shown to influence TNF- $\alpha$ gene expression and may induce IR [7]. Moreover, these polymorphisms have been involved in the pathogenesis and progression of NASH $[8$, 9]. Valenti et al. [9] reported that italian NAFLD patients have a high frequency of G-238A, but not of G-308A TNF- $\alpha$ polymorphisms in comparison with controls. In addition, these polymorphisms were associated with IR. Another report by Tokushige et al. [10] found that there were no significant differences in the genotype frequency of any of the five TNF- $\alpha$ polymorphisms (T-1031C, C-863A, C-857T, G-308A and G-238A) analyzed among Japanese NAFLD patients compared with healthy controls; however, the polymorphisms T-1031C and C-863A were associated with IR. On the other hand, a potentially functional amino acid polymorphism (Ala9Val) described in the mitochondrial targeting sequence (MTS) of manganese superoxide 
dismutase (MnSOD) has been associated with NASH development [11]. This polymorphism leads to a valine-toalanine amino acid change in the MTS $[12,13]$. This amino acid substitution affects the secondary structure of the MTS causing partial arrest of the precursor within the inner membrane and a decreased formation of the active MnSOD tetramer in the mitochondrial matrix, thus causing induced accumulation of ROS within the cells $[11,14]$. Based on this, the aim of this study was to determine whether the G-238A (allele TNFA), G-308A (allele TNF2) TNF- $\alpha$, and Ala9Val MnSOD polymorphisms were associated with NASH in a case-control study of subjects from Northeast Mexico.

\section{MATERIAL AND METHODS}

\section{Patients and Controls}

We included 92 patients over 18 years of age with a body mass index $(\mathrm{BMI}) \geq 35 \mathrm{~kg} / \mathrm{m}^{2}$ who underwent gastric bypass surgery at a single medical center in Monterrey, Mexico that cares for patients from the State of Nuevo Leon and surrounding states in Northeast Mexico (Coahuila, Tamaulipas, and San Luis Potosi). Studied patients underwent hepatic wedge biopsy at the time of gastric bypass surgery and a peripheral blood sample was drawn to perform molecular and laboratory tests.

NASH was diagnosed in 68 patients (50 women and 18 men; mean age \pm SD, $33.9 \pm 10.8$ years; BMI $43.9 \pm 7.2$ $\mathrm{kg} / \mathrm{m}^{2}$ ). The following laboratory tests were performed in all patients: aspartate aminotrasferase (AST), alanine aminotrasferase (ALT), alkaline phosphatase (ALP), $\gamma$-glutamyltransferase (GGT), as well as total cholesterol and triglycerides. Insulin resistance (IR) was evaluated by Quantitative Insulin Sensitivity Check Index $(\mathrm{QUICKI})=1 /\left[\log \left(\mathrm{I}_{0}\right)+\log \left(\mathrm{G}_{0}\right)\right]$ ), where $I_{0}$ is the fasting plasma insulin level (microunits per $\mathrm{mL}$ ), and $\mathrm{G}_{0}$ is the fasting blood glucose level (mg/dL) [16].

The control group included 100 unrelated healthy subjects who were residents of Northeast Mexico. A peripheral blood sample was collected from each. Forty-four were women and 56 were men. Mean age was $27.8 \pm 10.8$ years and mean BMI was $23 \pm 1.6 \mathrm{~kg} / \mathrm{m}^{2}$. All control subjects were confirmed to have normal liver function, no viral hepatitis infection by blood test, and no history of alcohol abuse. The research protocol was reviewed and approved by the institutional review board. At enrollment, all participants provided written informed consent.

\section{Biopsy Analysis}

Tissues were fixed in formaldehyde, embedded in paraffin, and stained with hematoxylin-eosin, silver reticulin, Sirius red for collagen, Perls' for iron and Masson's trichrome for assessment of liver fibrosis. All specimens were considered sufficient for analysis. Two pathologists blinded to clinical data reviewed biopsy specimens for hepatic steatosis, necroinflammatory activity, and liver fibrosis/cirrhosis according to the Brunt classification [3]. Fibrosis was scored using a 5-grade scale: F0, none or normal connective tissue; $\mathrm{F} 1$, foci of perivenular or pericellular fibrosis in zone 3; F2, perivenular or pericellular fibrosis confined to zones 3 and 2, with or without portal/periportal fibrosis; F3, bridging or septal fibrosis; and F4, cirrhosis [15].

\section{DNA Extraction}

Genomic DNA was obtained from peripheral blood leukocytes from patient's and control's samples using the standard phenol-chloroform method [17].

\section{Determination of TNF- $\alpha$ and MnSOD Polymorphisms}

Polymorphisms were detected in each DNA sample by the polymerase chain reaction-restriction fragment length polymorphism (PCR-RFLP) method. For the polymorphism of TNF- $\alpha$ promoter at position -238 we used the following primers: sense primer 5'-AGACCCCCCTCGGAACC-3' and antisense primer 5'-ATCTGGAGGAAGCGGTAGTG-3' [18]; while for the -308 TNF- $\alpha$ polymorphism we used the

Table 1. Demographic and Clinical Characteristics of NASH Patients and Controls

\begin{tabular}{|c|c|c|}
\hline Characteristics & $\begin{array}{c}\text { NASH patients } \\
n=68\end{array}$ & $\begin{array}{c}\text { Controls } \\
\mathbf{n}=100\end{array}$ \\
\hline Age (years; mean $\pm \mathrm{SD}$ ) & $33.9 \pm 10.8$ & $28 \pm 11$ \\
\hline \multicolumn{3}{|l|}{ Gender } \\
\hline Female & $50(74 \%)$ & $44(44 \%)$ \\
\hline \multicolumn{3}{|l|}{ Laboratory data } \\
\hline *Aspartate aminotransferase (U/L) & $7(58.7 \pm 10.9)$ & ------ \\
\hline *Alanine aminotransferase (U/L) & $8(98.5 \pm 34.8)$ & ------ \\
\hline$* \gamma$-glutamyltransferase (U/L) & $5(148.6 \pm 108.9)$ & ------ \\
\hline
\end{tabular}

* Patients with abnormal values above (at least one time) upper normal limit. Results are expressed as means \pm SD in parenthesis. All control subjects had normal values. 
sense primer 5'-CAATAGGTTTTGAGGGCCAT-3' (modified from Day et al. 1998) and the antisense primer describe above. These primers that contain a single base-pair mismatch adjacent to the polymorphism site to introduce a restriction site for the enzymes Msp I and Nco $I$ into the wild-type nucleotide sequences after amplification, were used to detect the polymorphisms -238 and -308 , respectively [7,19]. The amplified $151 \mathrm{bp}$ and $223 \mathrm{bp}$ products were digested with Msp I and Nco I restriction enzymes (New England BioLabs, Beverly, MA, USA) and analyzed using $2 \%$ agarose gel.

For the MnSOD MTS polymorphism (Ala9Val) we used the following primers [12]; sense primer 5'-CAGCCCAG CCTGCGTAGACGG-3' and antisense primer 5'-CTTGGCC AACGCCTCCTGGTACTT-3'. A PCR product of $267 \mathrm{bp}$ was obtained and then digested with $B s a W 1$ restriction enzyme (New England BioLabs, Beverly, MA, USA) and analyzed using $2 \%$ agarose gel.

\section{Statistical Analysis}

Results are expressed as means and standard deviations and were considered significant when $p<0.05$ (2-tailed). Hardy-Weinberg equilibrium was determined for these polymorphisms within the control group using $X^{2}$ test. Multivariate analysis was performed to assess the association between polymorphisms and several variables of phenotype expression of NASH. Data analysis was performed using Epi-Info version 3.3.2 and SPSS version 13.0 software.

\section{RESULTS}

\section{Demographic and Clinical Characteristics}

The demographic and clinical data of the 68 patients with NASH and 100 healthy subjects are shown in Table 1. All patients referred alcohol abstinence for a minimum of 4 years and none had ascites clinically or by ultrasonography, or obvious peripheral edema.

\section{TNF- $\alpha$ and MnSOD Polymorphisms}

The frequency of the -238 and -308 TNF- $\alpha$ polymorphisms (with the prevalence of TNFA and TNF2 alleles) in patients with NASH and controls are shown in Tables $\mathbf{2}$ and 3. No significant difference in the prevalence of -308 TNF- $\alpha$ polymorphism was observed among patients and controls; however, the prevalence of patients who carried the -238 TNF- $\alpha$ polymorphism was $29 \%$ and $12 \%$ in controls $(p=$ 0.0047 ) (Table 2). The allele frequencies of the TNFA and TNF2 alleles were 0.06 and 0.10 , respectively, and were in Hardy-Weinberg equilibrium $\left(X^{2}=0.407 ; p=0.5233\right.$ and $X^{2}=1.235 ; p=0.2665$, respectively).

Table 2. Allele and Genotype Distribution of the -238 TNF- $\alpha$ Polymorphism in NASH Patients and Controls

\begin{tabular}{|c|c|c|c|c|c|c|c|}
\hline Genotype & $\mathbf{n}$ & Genotype frequency $(\%)$ & Allele & $\mathbf{n}$ & Allele frequency $(\%)$ & $p$-Value & OR \\
\hline \multicolumn{8}{|l|}{ NASH } \\
\hline TNFG/TNFG & 48 & 71 & TNFG & 116 & 85 & 0.0047 & 3.06 \\
\hline TNFG/TNFA & 20 & 29 & TNFA & 20 & 15 & & \\
\hline TNFA/TNFA & 0 & 0 & & & & & \\
\hline Total & 68 & 100 & & 136 & & & \\
\hline \multicolumn{8}{|l|}{ CONTROL } \\
\hline TNFG/TNFG & 88 & 88 & TNFG & 188 & 94 & & \\
\hline TNFG/TNFA & 12 & 12 & TNFA & 12 & 6 & & \\
\hline TNFA/TNFA & 0 & 0 & & & & & \\
\hline Total & 100 & 100 & & 200 & & & \\
\hline
\end{tabular}

Table 3. Allele and Genotype Distribution of the -308 TNF- $\alpha$ Polymorphism in NASH Patients and Controls

\begin{tabular}{|c|c|c|c|c|c|c|c|}
\hline Genotype & $\mathbf{n}$ & Genotype frequency $(\%)$ & Allele & $\mathbf{n}$ & Allele frequency $(\%)$ & $p$-Value & OR \\
\hline \multicolumn{8}{|l|}{ NASH } \\
\hline TNF1/TNF1 & 54 & 79 & TNF1 & 122 & 90 & 0.925 & 1.04 \\
\hline TNF1/TNF2 & 14 & 21 & TNF2 & 14 & 10 & & \\
\hline TNF2/TNF2 & 0 & 0 & & & & & \\
\hline Total & 68 & 100 & & 136 & & & \\
\hline \multicolumn{8}{|l|}{ CONTROL } \\
\hline TNF1/TNF1 & 80 & 80 & TNF1 & 180 & 90 & & \\
\hline TNF1/TNF2 & 20 & 20 & TNF2 & 20 & 10 & & \\
\hline TNF2/TNF2 & 0 & 0 & & & & & \\
\hline Total & 100 & 100 & & 200 & & & \\
\hline
\end{tabular}


Table 4. Allele and Genotype Distribution of the Ala9Val MnSOD Polymorphism in NASH Patients and Controls

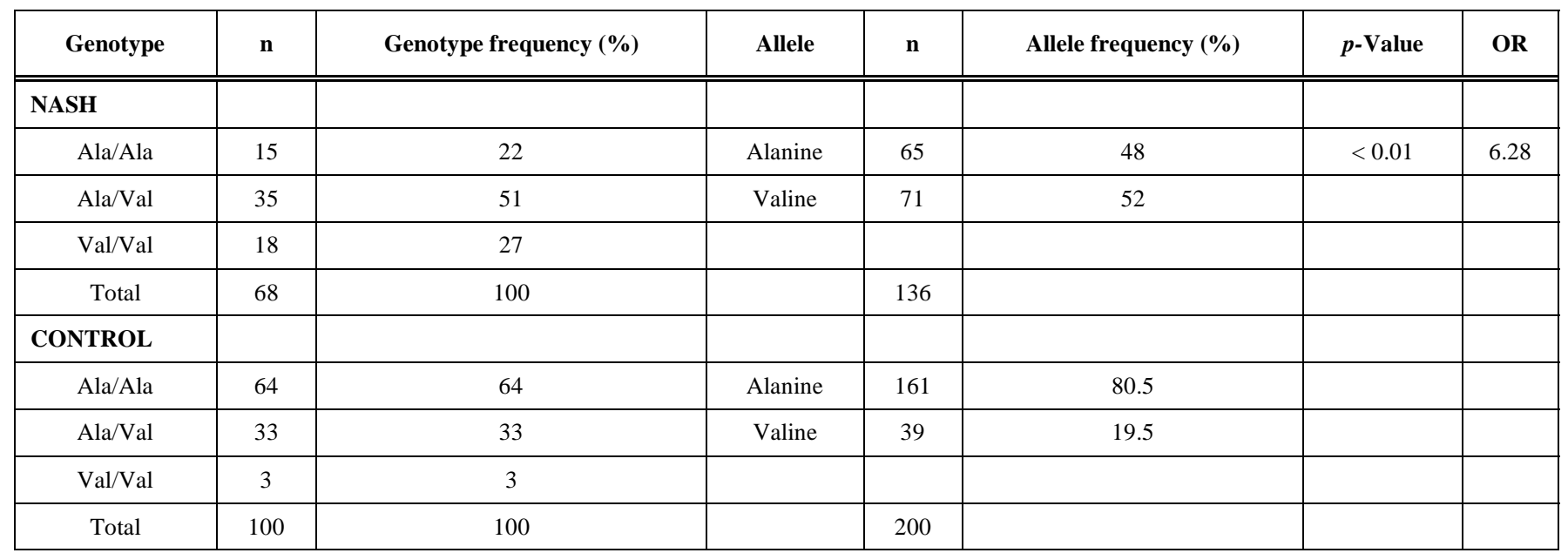

On the other hand, the frequency of MnSOD MTS Ala9Val polymorphism was significantly higher in patients with NASH than in control subjects (78\% vs. $36 \% ; p<0.01)$ (Table 4). The allele frequency of the Valine allele was 0.195 and was in Hardy-Weinberg equilibrium $\left(X^{2}=0.261\right.$; $p=0.6092$ ).

The frequency of G-238A TNF- $\alpha$ and Ala9Val MnSOD polymorphisms in NASH patients was significantly higher in comparison with control subjects (OR $=3.06$, 95\% CI 1.297.33, $p=0.0047$ and $\mathrm{OR}=6.28,95 \%$ CI 2.95-13.55, $p=0.001$, respectively).

\section{Relation between Polymorphisms Studied and Grade of Liver Fibrosis}

Finally, we analyzed the relationship between polymorphisms studied and grade of liver fibrosis, inflammation, and fatty deposits in NASH patients. Although fibrosis was found in all NASH patients studied (Fig. 1) we did not find any significant association between the three analyzed polymorphisms in comparison with the histological features observed (Table 5).

\section{DISCUSSION}

It has been recognized that some patients with NAFLD may follow a relatively benign course, whereas some others progress to NASH and its inherent complications [20,21]. Our study demonstrates that among otherwise asymptomatic, morbidly obese individuals undergoing gastric bypass surgery, the presence of moderate to severe hepatic steatosis is quite common as shown by the diagnosis of NASH identified in $74 \%(68 / 92)$ of cases initially included in the

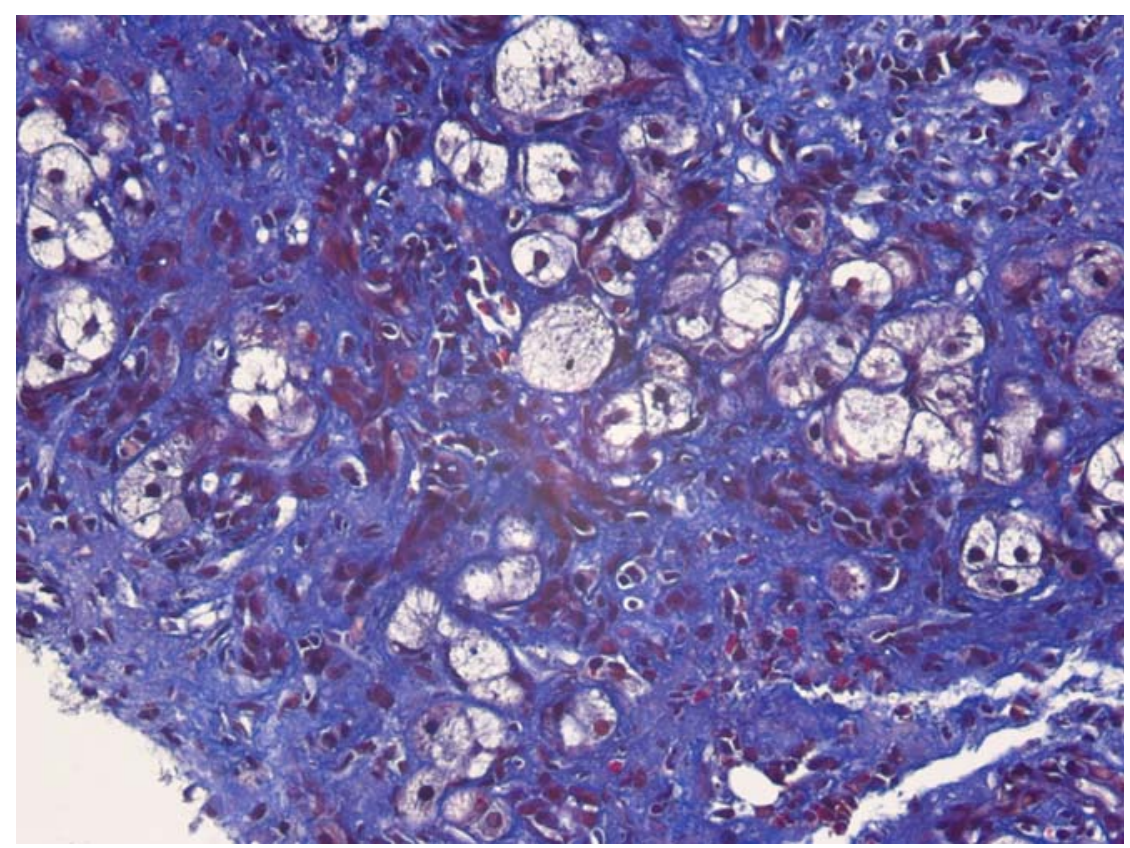

Fig. (1). A representative picture (20X) showing fibrosis in hepatic parenchyma from F2 patient liver biopsy. Tissue was fixed in formaldehyde, embedded in paraffin, and stained with Masson's trichrome for assessment of liver fibrosis. 
Table 5. Relationship between Liver Histological Features and TNF- $\alpha$ and MnSOD Polymorphisms in NASH

\begin{tabular}{|c|c|c|c|}
\hline \multirow{2}{*}{ Liver Histology } & \multicolumn{3}{|c|}{ Polymorphisms } \\
\cline { 2 - 4 } & $\mathbf{- 2 3 8}$ (TNFA carrier) & $\mathbf{- 3 0 8}$ (TNF2 carrier) & Ala9Val (Val carrier) \\
\hline \hline NASH & & $1.66(0.50-5.46, p=\mathrm{NS})$ & $0.35(0.10-1.18, p=\mathrm{NS})$ \\
\hline Mild & $1.57(0.55-4.48, p=\mathrm{NS})$ & $0.36(0.09-1.46, p=\mathrm{NS})$ & $1.31(0.39-4.38, p=\mathrm{NS})$ \\
\hline Moderate & $0.60(0.19-1.83, p=\mathrm{NS})$ & $1.83(0.40-8.23, p=\mathrm{NS})$ & $0.28(0.35-1.4, p=\mathrm{NS})$ \\
\hline Severe & $1.03(0.23-4.47, p=\mathrm{NS})$ & & $0.48(0.15-1.55, p=\mathrm{NS})$ \\
\hline FIBROSIS & & $0.80(0.23-2.73, p=\mathrm{NS})$ & $1.55(0.48-4.99, p=\mathrm{NS})$ \\
\hline F1 & $1.82(0.63-5.25, p=\mathrm{NS})$ & $0.75(0.22-2.45, p=\mathrm{NS})$ & $2.13(0.24-18.8, p=\mathrm{NS})$ \\
\hline F3 & $0.61(0.21-1.76, p=\mathrm{NS})$ & $2.67(0.55-12.89, p=\mathrm{NS})$ & \\
\hline
\end{tabular}

Results are expresed as odds ratio, $95 \%$ confidential interval, $p$-Value.

$p=\mathrm{NS}$, not significant

study (Table 1). Furthermore, we found that $12 \%$ of the population undergoing gastric bypass surgery had advanced fibrosis (grade 3) (Fig. 1). These results are similar to those previously reported in a retrospective analysis using postmortem data among morbidly obese patients where advanced fibrosis was found in $13.8 \%$ [22].

Although the pathogenesis of NASH in obese patients remains uncertain, it has been proposed that hepatic steatosis results from hyperinsulinemia and an inappropriately high level of free fatty acids [2,23]. Various risk factors have been associated with NASH, however, recently the role of genetic factors in the pathogenesis of this disease is receiving increasing attention [9-11]. Based on this, the aim of this study was to determine whether the G-238A (allele TNFA) and G308A (allele TNF2) TNF- $\alpha$ and Ala9Val MnSOD polymorphisms were associated with NASH in a case-control study of subjects from Northeast Mexico. We found that the frequency of the -238 TNF- $\alpha$ polymorphism was significantly higher in patients with NASH than in controls (29\% vs. $12 \%$; $p=0.0047$ ) (Table 2), while the prevalence of -308 was similar in patients and controls (21\% vs. 20\%; $p=0.925)$ (Table 3). Our results are in agreement with results found by Valenti et al. [9] who reported a high frequency of the -238 but not of the $-308 \mathrm{TNF}-\alpha$ polymorphism in Italian NAFLD patients. Tokushige et al. [10] reported that there were no significant differences in the frequency of $-1031,-863,-857$, -308 and -238 TNF- $\alpha$ polymorphisms among Japanese patients with NAFLD and controls. These discrepancies may have been due to ethnic differences or other factors. In this study, we found that the genotype distribution of the Ala9Val polymorphism was significantly higher in patients with NASH than in controls subjects $(78 \%$ vs. $36 \%$; $p<0.01)$ (Table 4). Similar results were found by Namikawa et al. [11] who reported that NASH patients also had a higher incidence of Ala9Val MnSOD polymorphism $(p=0.016)$. Recently, polymorphisms in other genes have been associated with the pathogenesis of NASH, such as microsomal triglyceride transfer protein (MTP) [11], adiponectin [24], methylenetetrahydrofolate reductase (MTHFR) [25], apolipoprotein $\mathrm{E}$, interleukin $1 \beta$, and $\beta 3$ adrenergic receptor [26].

In conclusion, our results suggest that G-238A TNF- $\alpha$ and Ala9Val MnSOD polymorphisms could be associated with NASH, although we did not find a direct relationship between the three analyzed polymorphisms and histological features. Further experiments, as gene expression of studied genes, should be performed in order to probe this hypothesis. These data may contribute to the understanding of the genetic susceptibility to NASH.

\section{ACKNOWLEDGEMENTS}

This study was partially supported by a grant from Autonomous University of Nuevo Leon to HGMR (PAICYT 2007-2008). We thank Sergio Lozano-Rodriguez, M.D. for his help in reviewing the manuscript.

\section{REFERENCES}

[1] Chitturi S, Abeygunasekera S, Farrell GC, et al. NASH and insulin resistance: Insulin hypersecretion and specific association with the insulin resistance syndrome. Hepatology 2002; 35: 373-9.

[2] Neuschwander-Tetri BA, Caldwell SH. Nonalcoholic steatohepatitis: summary of an AASLD Single Topic Conference. Hepatology 2003; 37: 1202-19.

[3] Brunt EM. Nonalcoholic steatohepatitis. Semin Liver Dis 2004; 24 3-20.

[4] Zafrani ES. Non-alcoholic fatty liver disease: an emerging pathological spectrum. Virchows Arch 2004; 444: 3-12.

[5] Alisi A, Nobili V. Molecular genetics of NASH: the role of polymorphisms. J Hepatol 2007; 47: 868-9; author reply 870-1.

[6] Osterreicher $\mathrm{CH}$, Brenner DA. The genetics of nonalcoholic fatty liver disease. Ann Hepatol 2007; 6: 83-8.

[7] Wilson AG, Symons JA, McDowell TL, et al. Effects of a polymorphism in the human tumor necrosis factor alpha promoter on transcriptional activation. Proc Natl Acad Sci USA 1997; 94: 3195-9.

[8] Crespo J, Cayon A, Fernandez-Gil P, et al. Gene expression of tumor necrosis factor alpha and TNF-receptors, p55 and p75, in nonalcoholic steatohepatitis patients. Hepatology 2001; 34: 1158-63.

[9] Valenti L, Fracanzani AL, Dongiovanni P, et al. Tumor necrosis factor alpha promoter polymorphisms and insulin resistance in nonalcoholic fatty liver disease. Gastroenterology 2002; 122: 27480 .

[10] Tokushige K, Takakura M, Tsuchiya-Matsushita N, et al. Influence of TNF gene polymorphisms in Japanese patients with NASH and simple steatosis. J Hepatol 2007; 46: 1104-10.

[11] Namikawa C, Shu-Ping Z, Vyselaar JR, et al. Polymorphisms of microsomal triglyceride transfer protein gene and manganese superoxide dismutase gene in non-alcoholic steatohepatitis. J Hepatol 2004; 40: 781-6.

[12] Degoul F, Sutton A, Mansouri A, et al. Homozygosity for alanine in the mitochondrial targeting sequence of superoxide dismutase 
and risk for severe alcoholic liver disease. Gastroenterology 2001; 120: 1468-74.

[13] Stewart SF, Leathart JB, Chen Y, et al. Valine-alanine manganese superoxide dismutase polymorphism is not associated with alcoholinduced oxidative stress or liver fibrosis. Hepatology 2002; 36: $1355-60$.

[14] Mitrunen K, Sillanpaa P, Kataja V, et al. Association between manganese superoxide dismutase (MnSOD) gene polymorphism and breast cancer risk. Carcinogenesis 2001; 22: 827-9.

[15] Brunt EM. Nonalcoholic steatohepatitis: definition and pathology. Semin Liver Dis 2001; 21: 3-16.

[16] Katz A, Nambi SS, Mather K, et al. Quantitative insulin sensitivity check index: a simple, accurate method for assessing insulin sensitivity in humans. J Clin Endocrinol Metab 2000; 85: 2402-10.

[17] Sambrook J, Russell DW, Sambrook J. Molecular Cloning: A Laboratory Manual (3-Volume Set). Cold Spring Harbor Laboratory Press, 2001.

[18] Day CP, Grove J, Daly AK, et al. Tumour necrosis factor-alpha gene promoter polymorphism and decreased insulin resistance. Diabetologia 1998; 41: 430-4.

[19] Wilson AG, di Giovine FS, Blakemore AI, et al. Single base polymorphism in the human tumour necrosis factor alpha (TNF alpha) gene detectable by NcoI restriction of PCR product. Hum Mol Genet 1992; 1: 353.
[20] Matteoni CA, Younossi ZM, Gramlich T, et al. Nonalcoholic fatty liver disease: a spectrum of clinical and pathological severity. Gastroenterology 1999; 116: 1413-9.

[21] Clark JM, Brancati FL, Diehl AM. Nonalcoholic fatty liver disease. Gastroenterology 2002; 122: 1649-57.

[22] Wanless IR, Lentz JS. Fatty liver hepatitis (steatohepatitis) and obesity: an autopsy study with analysis of risk factors. Hepatology 1990; 12: 1106-10.

[23] Beymer C, Kowdley KV, Larson A, et al. Prevalence and predictors of asymptomatic liver disease in patients undergoing gastric bypass surgery. Arch Surg 2003; 138: 1240-4.

[24] Musso G, Gambino R, De Michieli F, et al. Adiponectin gene polymorphisms modulate acute adiponectin response to dietary fat: Possible pathogenetic role in NASH. Hepatology 2008; 47: 116777.

[25] Sazci A, Ergul E, Aygun C, et al. Methylenetetrahydrofolate reductase gene polymorphisms in patients with nonalcoholic steatohepatitis (NASH). Cell Biochem Funct 2008; 26: 291-6.

[26] Nozaki Y, Saibara T, Nemoto Y, et al. Polymorphisms of Interleukin- $1 \beta$ and $\beta 3$-Adrenergic Receptor in Japanese Patients With Nonalcoholic Steatohepatitis. Alcoholism: Clin Exper Res (2004); 28: 106S-110S.

(C) Trujillo-Murillo et al.; Licensee Bentham Open.

This is an open access article licensed under the terms of the Creative Commons Attribution Non-Commercial License (http://creativecommons.org/licenses/bync/3.0/), which permits unrestricted, non-commercial use, distribution and reproduction in any medium, provided the work is properly cited. 